Research Article

www.ijrap.net

\title{
THE STUDY OF THE RELEVANCE ON THE ESTABLISHMENT OF DRUG INFORMATION CENTRE AT A SECONDARY HOSPITAL IN SOUTH WEST NIGERIA
}

Omole Moses Kayode*, Abdus-Salami F. Yetunde

Department of Clinical Pharmacy and Pharmacy Administration, Faculty of Pharmacy, University of Ibadan, Nigeria

Received on: 23/04/12 Revised on: 05/06/12 Accepted on: 02/07/12

\author{
*Corresponding author \\ Dr Moses Kayode Omole, Dept. of Clinical Pharmacy and Pharmacy Administration, Faculty of Pharmacy, University of Ibadan, Nigeria \\ Email: kayodeomole06@yahoo.com \\ DOI: 10.7897/2277-4343.03526 \\ Published by Moksha Publishing House. Website www.mokshaph.com \\ All rights reserved.
}

\begin{abstract}
This prospective study was carried out in a state hospital, Sokemu, Abeokuta to determine the relevance of Drug Information Centre (DIC) to the practice of Health Care Professionals in the Hospital.

A total of 120 questionnaires were administered to the hospital health care professionals. Total number of respondents was 107 corresponding to $89.2 \%$ of the total population with years of experience in service ranging from $5-15$ years.

Eighty five $85(79.4 \%)$ believed that Drug Information Centre was relevant to their professional practice, $12(11.2 \%)$ believed that it was not relevant to their professional practice, while $10(9.4 \%)$ were not sure of the relevance of the DIC to their professional practice.

Forty three (43) (19.2\%) respondents required latest Information on drugs, $25(11.2 \%)$ required information on side effects, 29 (12.9\%) on dosage form, $27(12.1 \%)$ on dosage regimen, $12(5.4 \%)$ on indications, $27(12.1 \%)$ on contra-indications, $19(8.5 \%)$ on brand names and $21(9.4 \%)$ required drug information on all the listed areas.

Forty seven (47) (43.9\%) claimed that they obtained Drug Information from relevant textbooks, 74 (69.2\%) from colleagues, 16 (15.0\%) from internet, $23(21.5 \%)$ from journal and largest number $102(95.3 \%)$ claimed they obtained information from the Pharmacists who are medical representatives of pharmaceutical companies as well as from hospital pharmacists.

Drug Information Centre was found to be relevant to the practice of health care professionals at a state hospital, Sokemu in Abeokuta, Nigeria. Hypothesis testing showed significant relationship of $\mathrm{p}<0.05$.

Keywords: Drug Information, Drug information services, Drug information center, Health care professionals, Relevance, Pharmacists
\end{abstract}

\section{INTRODUCTION}

Information is regarded worldwide as a powerful tool in decision making management. The question is often asked if information on drugs is a pharmacist role. Only recently has it been generally accepted that medicines should be defined as active substance plus information ${ }^{1}$. This implies that both components (substance and information) are equally important. In the 1950's there were relatively few drugs some of which turned out to be unacceptably toxic. Today there are thousands of drugs in the market, many in each therapeutic category ${ }^{2}$.

Biomedical information has also expanded in complexity and quantity, so that information is fast outstripping the ability of professionals to analyze and integrate. In most countries, the number of drugs in the market is greater than is medically required, making a choice by the medical practitioner a serious problem, especially where objective information is lacking. This can lead to irrational drug prescribing which undermine health services and injure patients ${ }^{3}$. The ability of the pharmacists to provide up to date information on drugs is an important skill for all pharmacists ${ }^{1}$. The use of drugs in the society is widespread and therefore information on their safety, appropriateness and efficacy is necessary ${ }^{2}$. Drug information system is often regarded as an integral part of pharmaceutical care which has to be managed by a pharmacist as one of his roles as a member of Healthcare team ${ }^{1}$.

Drug information service is paramount to the successful operation of any health care delivery system. The idea of involving pharmacists into the decision making process of optimal care originated within the drug information concept. This is particularly true in those hospitals or communities who regularly provide drug information to patients during counseling, to nurses on routes of administration and dosing interval if not stated by doctors as well as to physicians so as to improve their prescriptions skills ${ }^{2,3}$.

The establishment and maintenance of a drug formulary requires that drugs and drugs classes be objectively accessed based on scientific information such as efficacy, safety, uniqueness, costs, indications, contradictions, dosages, dosage form, dosage regimen and generic names and not anecdotal physician experience ${ }^{4-7}$.

The way to decide which drug is best for formulary addition, is to rationally evaluate all aspects of scientific information in relation to similar agents ${ }^{4,8}$. This forms the basis for the establishment of Drug Information Center (DIC).

This study aims at the relevance and the establishment of DIC at a state hospital in Sokenu Abeokuta with the goal of providing and promoting pharmaceutical care.

\section{PATIENTS AND METHODS}

120 health care professionals were randomly selected from those who volunteered to participate in the study. Only 107 health care professionals eventually returned the questionnaires administered.

Hospitals where Drug Information Centres were already in existence included Nnamdi Azikwe Teaching Hospital, 
Nnewi and Lagos University Teaching Hospital, Idi-araba Lagos. Visits were paid to these hospitals to determine the operation of DIC for favorable comparison.

Data was collected and analyzed using Descriptive Statistics of frequency distribution and percentages. Quantitative analysis was carried out using Chi - Square with the aid of the Statistical Package for Social Sciences (SPSS) 10.0 Window version.

Ethical approval was granted by the Health Services Committee of Ogun State Hospitals Management Board, State Hospital, Sokemu, Abeokuta, Ogun State, Nigeria with ethical clearance reference number: SHA.35/Vol.1/8 dated $29^{\text {th }}$ June 2005.

Table 1: Socio Demographic characteristics of Health care

\begin{tabular}{|c|c|c|}
\hline \multicolumn{3}{|c|}{ professionals } \\
\hline Sex & Frequency & \% Distribution \\
\hline Male & 47 & 43.9 \\
\hline Female & 60 & 56.1 \\
\hline Total & 107 & 100.0 \\
\hline Age & Frequency & \% Distribution \\
\hline $21-30$ & 22 & 20.6 \\
\hline $31-40$ & 37 & 34.6 \\
\hline $41-50$ & 31 & 28.9 \\
\hline 51 and above & 17 & 15.9 \\
\hline Total & 107 & 100.0 \\
\hline Marital status & Frequency & \% Distribution \\
\hline Single & 21 & 19.6 \\
\hline Married & 86 & 80.4 \\
\hline Total & 107 & 100.0 \\
\hline Religion & Frequency & \% Distribution \\
\hline Islam & 28 & 26.2 \\
\hline Christianity & 77 & 71.9 \\
\hline Traditional religion & 02 & 1.9 \\
\hline Total & 107 & 100.0 \\
\hline Years in Service & Frequency & \% Distribution \\
\hline 5 & 27 & 25.2 \\
\hline $6-10$ & 22 & 20.6 \\
\hline $11-15$ & 12 & 11.2 \\
\hline $16-20$ & 15 & 14.1 \\
\hline $21-25$ & 13 & 12.1 \\
\hline 26 and above & 18 & 16.8 \\
\hline Profession & Frequency & \% Distribution \\
\hline Physicians & 25 & 23.4 \\
\hline Pharmacists & 8 & 7.5 \\
\hline Nurses & 62 & 57.9 \\
\hline Lab. Scientists & 7 & 6.5 \\
\hline Physiotherapists & 3 & 2.8 \\
\hline Radiographers & 1 & 0.9 \\
\hline Optometrists & 1 & 0.9 \\
\hline Total & 107 & 100.0 \\
\hline
\end{tabular}

\section{RESULTS}

Table 1 shows females 60 (56.1\%) were more than males 47 (43.9\%) with age distribution being 22(20.6\%) participants aged between 21-30 years while 37 (34.6\%), $31(28.9 \%)$ and $17(15.5 \%)$ participants aged between 31 40 years, 41-50 years and 50 years and above respectively.

There were $25(23.4 \%)$ physicians $8(7.5 \%)$ pharmacists $62(57.9 \%)$ nurses and laboratory scientists, physiotherapists, radiographers and optometrists being 7 $(6.5 \%), 3(2.8 \%), 1(0.9 \%)$ and $1(0.9 \%)$ respectively with the years of service ranging from $5(25.2 \%)$ years and 26 $(74.8 \%)$ years and above for 27 and 18 health care professional respectively.
Table 2 shows the response to the establishment of drug information centers by health professionals. Out of the total number of 52 nurses, $41(66.1 \%)$ agreed to the relevance of drug information center to their professional practice, $12(19.45 \%)$ did not agree while 9 (14.5\%) were indifferent. $8(100 \%)$ pharmacist, 25 (100\%) physicians, 7 $(100 \%)$ laboratory scientists and $3 \quad(100 \%)$ physiotherapists agreed that drug information center was relevant to their professional practice and the only 1 $(100 \%)$ optometrist agreed that drug information center was relevant to its practice while the only radiographer $1(100 \%)$ who participated in the study was indifferent.

Table 3 shows the type of drug information often required. $25(11.2 \%)$ health care workers require information on side effects, $29(\% 12.9)$ on dosages, 21 $(9.4 \%)$ on dosage forms, $27(12.1 \%)$ on dosage regimen, $43(19.2 \%$.) on latest information on drugs while 12 $(5.4 \%), 27(12,1 \%), 19(8.4 \%)$ and $21(9.4 \%)$ required drug information on indications, contradictions, brand names and all the information on drugs respectively.

Table 4 shows the breakdown of sources of drug information often used by the professionals 17, 49, 3 and 61 nurses depended on text books, colleagues, journals and pharmacists respectively. Pharmacists and physicians used all the available sources to obtain drug information. 4, 3, 2, 1, 8 and 7 pharmacists depended on textbooks, colleagues, internet, journals, pharmacists and others respectively while $24,20,14,19,21$ and 9 physicians depended on textbooks, colleagues, internet, journals, pharmacists and others respectively. 2 and 7 laboratory scientists depended on textbooks and pharmacists while 2 and 3 physiotherapists depended on colleagues and pharmacists respectively. The only radiographer and the only optometrist that participated in the study both depended on pharmacist to obtain drug information.

From the hypothesis Testing, the value of $\mathrm{P}$ was found to be less than $0.05(\mathrm{P}<0.05)$ while the obtained $\mathrm{P}$ value was 0.006. The Null Hypothesis stating that the establishment of Drug Information Centre in State Hospital, Abeokuta is not relevant to the practice of health care professional in the Hospital has to be rejected.

\section{DISCUSSION}

The nature of drug information is that it is constantly evolving because of ongoing research and clinical experience often subject to interpretation and the uniqueness of each clinical situation and patient ${ }^{8,9}$.

The term drug information developed in the early 1960's when used in conjunction within the words 'centre' and 'specialist.' In 1962 the first drug information center was opened at the University of Kentucky Medical Center. An area separated from pharmacy department was dedicated to provide drug information. The center was to be a source of selected comprehensive drug information for staff, physicians, and dentist to evaluate and compare information on drugs as well as to provide for the drug information needs of nurses. The health professionals who participated in this study included physicians, pharmacists and nurses. (Table 2) 
Omole Moses Kayode et al / IJRAP 3(5), Sep - Oct 2012

Table 2: Relevance of Drug information Centre based on profession

\begin{tabular}{|c|c|c|c|c|c|}
\hline & & \multicolumn{3}{|c|}{$\begin{array}{l}\text { Do you think a drug information } \\
\text { centre in state hospital Abeokuta is } \\
\text { relevant to your profession practice }\end{array}$} & \multirow[b]{2}{*}{ Total } \\
\hline \multicolumn{2}{|c|}{ Profession } & Yes & No & Indifferent & \\
\hline Nurses & $\begin{array}{l}\text { Count } \\
\% \text { within profession }\end{array}$ & $\begin{array}{c}41^{\prime} \\
66.1 \%\end{array}$ & $\begin{array}{c}12 \\
19.4 \%\end{array}$ & $\begin{array}{c}9 \\
14.5 \%\end{array}$ & $\begin{array}{c}62 \\
100.0 \%\end{array}$ \\
\hline Pharmacists & $\begin{array}{l}\text { Count } \\
\% \text { within profession }\end{array}$ & $\begin{array}{c}8 \\
100.0 \%\end{array}$ & & & $\begin{array}{c}8 \\
100.0 \%\end{array}$ \\
\hline Physicians & $\begin{array}{l}\text { C ount } \\
\% \text { within profession }\end{array}$ & $\begin{array}{c}25 \\
100.0 \%\end{array}$ & & & $\begin{array}{c}25 \\
100.0 \%\end{array}$ \\
\hline Lab Scientists & $\begin{array}{l}\text { Count } \\
\% \text { within profession }\end{array}$ & $\begin{array}{c}7 \\
100.0 \% \\
\end{array}$ & & & $\begin{array}{c}7 \\
100.0 \% \\
\end{array}$ \\
\hline Physiotherapists & $\begin{array}{l}\text { Count } \\
\% \text { within profession }\end{array}$ & $\begin{array}{c}3 \\
100.0 \% \\
\end{array}$ & & & $\begin{array}{c}3 \\
100.0 \% \\
\end{array}$ \\
\hline Radiographer & $\begin{array}{l}\text { Count } \\
\% \text { within profession }\end{array}$ & & & $\begin{array}{c}1 \\
100.0 \% \\
\end{array}$ & $\begin{array}{c}1 \\
100.0 \% \\
\end{array}$ \\
\hline Optometrists & $\begin{array}{l}\text { Count } \\
\% \text { within profession }\end{array}$ & $\begin{array}{c}1 \\
100.0 \%\end{array}$ & & & $\begin{array}{c}1 \\
100.0 \%\end{array}$ \\
\hline Total & $\begin{array}{l}\text { Count } \\
\% \text { within profession }\end{array}$ & $\begin{array}{c}85 \\
79.4 \% \\
\end{array}$ & $\begin{array}{c}12 \\
11.2 \%\end{array}$ & $\begin{array}{c}10 \\
9.4 \%\end{array}$ & $\begin{array}{c}107 \\
100.0 \%\end{array}$ \\
\hline
\end{tabular}

Table 3: Type of Information often required by the Health care professionals

\begin{tabular}{|c|c|}
\hline Information often required & Number of Respondents \\
\hline Side effect & 25 \\
\hline Dosages & 29 \\
\hline Dosage forms & 21 \\
\hline Latest information on drug & 43 \\
\hline Dosage regimen & 27 \\
\hline Indications & 12 \\
\hline Contra indicators & 27 \\
\hline Brand names & 19 \\
\hline All of the above & 21 \\
\hline
\end{tabular}

*Multiple responses

Table 4: Sources of Drug information used by the Health care professionals

\begin{tabular}{|c|c|c|c|c|c|c|c|}
\hline & Books & Colleagues & Internet & Journals & Pharmacists & Others & Total \\
\hline Nurses & $17(13.0 \%)$ & $\begin{array}{c}49 \\
(37.7 \%)\end{array}$ & 0 & $\begin{array}{c}3 \\
(2.3 \%)\end{array}$ & $\begin{array}{c}61 \\
(46.9 \%)\end{array}$ & 0 & $\begin{array}{c}130 \\
100 \%\end{array}$ \\
\hline Pharmacists & $\begin{array}{c}4 \\
(16.0 \%)\end{array}$ & $\begin{array}{c}3 \\
(12.0 \%)\end{array}$ & $\begin{array}{c}2 \\
(8.0 \%)\end{array}$ & $\begin{array}{c}1 \\
(4.0 \%)\end{array}$ & $\begin{array}{c}8 \\
(32.0 \%)\end{array}$ & $\begin{array}{c}7 \\
(28.0 \%)\end{array}$ & $\begin{array}{c}25 \\
100 \%\end{array}$ \\
\hline Physicians & $\begin{array}{c}24 \\
(22.45)\end{array}$ & $\begin{array}{c}20 \\
(18.7 \%)\end{array}$ & $\begin{array}{c}14 \\
(13.1 \%)\end{array}$ & $\begin{array}{c}19 \\
(17.8 \%)\end{array}$ & $\begin{array}{c}21 \\
(19.65)\end{array}$ & $\begin{array}{c}9 \\
(8.4 \%)\end{array}$ & $\begin{array}{c}107 \\
100 \%\end{array}$ \\
\hline Lab. Sci. & $\begin{array}{c}2 \\
(22.2 \%)\end{array}$ & 0 & 0 & 0 & $\begin{array}{c}7 \\
(77.8 \%)\end{array}$ & 0 & $\begin{array}{c}9 \\
100 \%\end{array}$ \\
\hline Physiothera & 0 & $\begin{array}{c}2 \\
(40.0 \%)\end{array}$ & 0 & 0 & $\begin{array}{c}3 \\
(60.0 \%)\end{array}$ & 0 & $\begin{array}{c}5 \\
100 \%\end{array}$ \\
\hline Radiograph & 0 & 0 & 0 & 0 & $\begin{array}{c}1 \\
(100 \%)\end{array}$ & 0 & $\begin{array}{c}1 \\
100 \% \\
\end{array}$ \\
\hline Optomet & 0 & 0 & 0 & 0 & $\begin{array}{c}1 \\
(100 \%)\end{array}$ & 0 & $\begin{array}{c}1 \\
100 \%\end{array}$ \\
\hline
\end{tabular}

The pharmacist is expected to organize drug information and disseminate it efficiently so as to ensure the effective management of the drug needs of the patients. Drug information is communicated to the patients and the health care professionals. The area where drug information services are important include adverse drug reaction, drug interactions, drug of choice, dosage regimen, route of administration, duration of therapy, drug storage and $\operatorname{cost}^{5,6,8}$. In this study, the health professionals who participated sought drug information on side effects, dosages, dosage form, dosage regimen, indications, contraindications, and brand names. (Table 3 ) The drug evaluation monograph provides a structured method to review the major features of a drug product. Once a monograph is prepared, it can easily be used as a structured template or overview of a drug product. This allows for easy comparison or contrast to other products that may be used for the same medication or that are in the same product class $5,6,9,10$.

Drug monographs available serves as tertiary drug information resources. They include American hospital Formulary Service (AHFS) prepared by American Society of Health System Pharmacist (ASHSP), British Pharmacopia Codex (BPC), United States Pharmacopia (USP), National Formulary (NF), United States Adopted Names (USAN), Dictionary Of Drugs Names, Drug Facts and Comparison which is updated monthly and bound annually $5,11,12$.

These references may often serve as an initial place to identify information due to the fact that they provide a fairly complete and concise overview of information available on a specific topic. These resources are convenient, easy to use, and familiar to most practitioners. Most of the information needed by a practitioner can be found in these sources, making these excellent first-line 
resources when dealing with a drug information question $^{13,14 .}$

The major drawback to tertiary resources, however, is the lag time associated with publication, resulting in less current information. Medical information changes so rapidly that it is possible that information may be out of date before it is even published. It is also possible that information in a tertiary text may be incomplete due either to space limitations of the book or incomplete literature searches by the author. Other problems that can be seen with tertiary information include errors in transcription, human bias, incorrect interpretation of information or lack of expertise by authors. For these reasons readers must judge the quality of tertiary references $^{15}$.

In this study, pharmacists, physicians and nurses depended on textbooks which are a tertiary source of drug information. These health professionals are the most prominent health professionals in the hospital (Table 4).

Information extracted from this study shows the important role that the pharmacists play in the dissemination of objective, reliable, up-to-date and unbiased information on drugs in the health care delivery system.

The responsibilities of individual pharmacist regarding the provision of medication information have changed substantially over the years. Impetus for the change was provided not only by the development of drug information centers and clinical pharmacy concept but also by the study commission on pharmacy.

This external group (study commission on pharmacy) was established in 1975 by the United States of America (USA) government to review the state of practice and education of pharmacist and report its findings. One of the findings and recommendation stated that "Among deficiencies in the health care system one is the unavailability of adequate information for those who consume, prescribe, dispense and administer drugs. This deficiency has resulted in inappropriate drug use and an unacceptable frequency of induced disease. Pharmacists are seen as health professionals who could make an important contribution to the health care system of the future by providing information about drugs to consumers and health professionals. Education and training of pharmacist now and in the future must be developed to meet these important responsibilities"

Since the report of the commission in 1975, drug information practice has changed both for drug information centers and individual pharmacists. The development of clinical pharmacy has helped move pharmacy forward in recognizing its capabilities to contribute to the care of patients. Clinical pharmacy was primarily thought to be an institutional patient care process and did not gain widespread acceptance outside hospitals. Overtime the activity of pharmacist as a medication expert for patients has gained acceptance in a variety of practice settings including community pharmacy, nursing homes and primary and specialty practices in medicine ${ }^{19-21}$. Pharmacists who provide patient specific information with a goal of improving patient's outcome use the medical literature such as found in primary, secondary and tertiary sources of information to support their choices 22,23 .
In this study, all the health professionals that participated depended on pharmacists to provide information on drugs for them. This shows the importance of pharmacists in the establishment of drug information center (DIC). It also indicates the awareness of health professionals to recognize clinical pharmacists' role in the health care delivery system in the provision of pharmaceutical care aspect of drug information (Table 4).

\section{CONCLUSION}

Information on drug safety, management, appropriateness and efficacy is necessary. This calls for an effective Drug Information System which is supposed to be an integral part of pharmaceutical care in health care delivery system. Drug information service is therefore paramount to the successful operation of any health care delivery system.

\section{ACKNOWLEDGEMENT}

We acknowledge the technical support and cooperation of the health care professionals at the state hospital, Sokemu, Abeokuta who voluntarily participated in the study.

\section{REFERENCES}

1. Anyim JSK. Communication and Information Services, An essential part in Clinical Pharmacy. Journal of West African Pharmacy1992; 6: 1-5

2. Omole MK. Drug Information Service: Lecture Delivered at Mandatory Continuing Professional Development Programme organized by Pharmacists Council of Nigeria 1998;4: 1-7.

3. Sue Brizuela, JA Nesp. Drug Information in Remington Pharmaceutical Sciences 1990. $18^{\text {th }}$ Ed. 49-58

4. Ossy J Kusilo, Charles FB. Recommendations for Establishing a drug and Toxicology Information Centre in a Developing Country. DIP. The Annals of Pharmacotherapy 1991;25: 1379-1383

5. Patrick M. Malone et al. Drug Information - a guide for pharmacists. 2006. $3^{\text {rd }}$ Ed. 1-66.

6. Hach - Isabel, Mansel-Dirk, Maywald-Ulf. Drug Information centres - Instrument for Health Care Research? Medizinische Klinik. 2005;10(7): 396-400

7. Soraya D, Catherine D, Anne J. What Part Pharmacists Should Play in Providing Medicines relations Information. The Pharmaceutical Journal 2001;266: 364-366

8. Smith S, Bottle R. Use of information Services by Drug Information Pharmacists. The Pharmaceutical Journal 1994;253: 499-507.

9. Mandalina Rusa, Augustin Prodan. A Web-based Drug Information centre for Health Care Professionals Abstract from http:/www.actapress.com/PDF Viewer.aspx retrieved 30/1/2006

10. David, Bawden. Computers and the Pharmacists. The Pharmaceutical Journal 1997;259: 221-227

11. Pharmacy Community Care Liason Group. Patient Information on Medicines - Developing Pharmacy's Contribution to Local Strategies. The Pharmaceutical Journal 1996;257: 71-72

12. Omole MK. et al. Pharmacoecomics evaluation of antimicrobial therapy at a secondary health facility in Minna, Nigeria. J. Pharm Biomed Sci. 2011;1(5)108-112

13. Norman Westwood. Communication and the Pharmacist. British Journal of Pharmaceutical Practice 1985; 7: 278-280

14. Erin M Timpe, Susana EM. Frequency and Complexity of Queries to an Academic Drug Information Centre, American Journal of Health System Pharmacy 2005;62: 2511-2513 http://dx.doi.org/10.2146/ajhp050063 PMid:16303908

15. Amy F, Kevin G, Cathy L. Expansion of Drug Information Services in Response to an Increased Clerkship Teaching Load. American Journal Of Health System Pharmacy 2005;62: 2514-2515 http://dx.doi.org/10.2146/ajhp050287 PMid:16303909

16. Wawruch M. et al. The Evaluation of the profile of Users of Drug Information Centres, (1997-2004), Bratislavske Lekarske (Brastisllek-listyl) in Medline Abstract 169261409 2006;106(3): 133-136

17. Racheal Ann Cochran et al. A Multidisciplinary Approach to Drug Information Provision. The Pharmaceutical journal 1995;254: 870875 
18. Traq Muhammed et al. Community Drug Information Services. The Pharmaceutical Journal 1998;260: 278-279

19. Andrew Robson et al. Medical Information services in Pharmaceutical Industry: A Survey of Pharmacists' Views with Recommendations. The Pharmaceutical Journal 1995;256:22-26

20. Information on Campbell university School of Pharmacy Drug information Centre. From www.campbell.edu/pharmacy/druginfo Retrieved on 30/1/2006

21. Smith Jim et al. Drug information Comes of Age. British journal of Pharmaceutical Practice 1985;193-196
22. Tayo Fola et al. The Pharmacist in Public health: Challenges of the millennium. West African Journal of Pharmacy 2001;15(1):11-22

23. Rosenberg JM et al. Current Status of Pharmacist - Operated Drug Information centre in the United State, American Journal of Health System Pharmacy 2004;61: 2023-2032

Cite this article as:

Omole Moses Kayode, Abdus-Salami F. Yetunde. The study of the relevance on the establishment of drug information centre at a secondary hospital in South west Nigeria. Int. J. Res. Ayur. Pharm. 2012; 3(5):710714 